\title{
CARACTERIZAÇÃO BIOQUÍMICA DE ISOLADOS BACTERIANOS DE SOLO DE CULTIVO DE VIDEIRA (Vitis sp.)
}

\author{
Alchieri, MS*, Gelinski, JMLN*, Minotto, $E^{* * *}$
}

Resumo

A viticultura é uma atividade importante para a sustentabilidade da pequena propriedade no Brasil, produzindo uvas de mesa e para o processamento. Nesse sentido, realizou-se um estudo biosprospectivo para avaliar a diversidade da microbiota de solos utilizados no cultivo da videira. Foram coletadas amostras de solo de cultivares de municípios da zona rural do Meio-Oeste de Santa Catarina. Foram obtidos 21 isolados bacterianos. A identificação bioquímica revelou que $88,88 \%$ dos isolados gram-negativas foram da espécie Shigella dysenteriae soro grupo A e $11,11 \%$ da espécie Pseudomonas oryzihabitans. Em relação ao perfil de sensibilidade a antimicrobianos, $100 \%$ dos isolados foram sensíveis a três dos antibióticos (Gentamicina, Pipemídico e Cloranfenicol), mas 100\% dos isolados foram resistentes aos antibióticos Ceftazidina e Aztreonam. Para as gram-positivas foram identificadas as espécies Bacillus cereus, B. megaterium, Corynebacterium xerosis e C. pseudodiphtheriticum. Em

\footnotetext{
* Graduada em Engenharia de Alimentos pela Universidade do Oeste de Santa Catarina de Videira; moaraa01@gmail.com

${ }^{*}$ Doutora em Ciência dos Alimentos pela Universidade de São Paulo; Mestre em Genética pela Universidade Federal do Rio Grande do Sul; Professora do Programa de Pós-graduação em Ciência e Biotecnologia na Universidade do Oeste de Santa Catarina; Rua Paese, 198, Universitário, 89560-000, Videira, Santa Catarina, Brasil, Pós-doutora pela Universidade Federal do Paraná; jane.gelinski@unoesc.edu.br

${ }^{* * *}$ Doutora em Microbiologia Agrícola e do Ambiente pela Universidade Federal do Rio Grande do Sul; Mestre em Fitossanidade pela Universidade Federal de Pelotas; Professora do Programa de Pós-graduação em Ciência e Biotecnologia na Universidade do Oeste de Santa Catarina; elisandra.minotto@unoesc.edu.br
} 
ambos os grupos observaram-se características de importância para a seleção de microorganismos com potencial para a disponibilização de nutrientes no solo, contribuindo para o desenvolvimento de plantas, destacando-se as espécies $P$. oryzihabitans e B. megaterium. Considera-se que a caracterização desses microorganismos contribui para a avaliação da diversidade da microbiota do solo, bem como para a definição de uso desses microorganismos em outros estudos de interesse biotecnológico. Palavras-chave: Uva. Biodiversidade. Biotecnologia. Agricultura.

\title{
Biochemical characterization of bacterial isolates of vine cultivation soil (vitis sp.)
}

\begin{abstract}
Viticulture is an important activity for the sustainability of small properties in Brazil, producing table grapes and for processing. In this sense, a preliminary biosprospective study was carried out to evaluate the diversity of soil microbiota used in vine growing. Soil samples were collected from several cultivars of municipalities in the rural area of Santa Catarina. Twenty-one bacterial isolates were obtained. Biochemical identification revealed that $88.88 \%$ of the gram negative isolates were Shigella dysenteriae serum group $A$ and $11.11 \%$ as Pseudomonas oryzihabitans. Regarding the antimicrobial sensitivity profile, $100 \%$ of the isolates were sensitive to three of the antibiotics (Gentamicin, Pipemidic and Chloramphenicol), but $100 \%$ of the isolates were resistant to the antibiotics Ceftazidine and Aztreonam. For the gram positive isolates the species Bacillus cereus, B. megaterium, Corynebacterium xerosis and C. pseudodiphtheriticum were identified. In both groups important characteristics were observed for the selection of microorganisms with potential for the availability of nutrients in the soil, contributing to the development of plants, especially the species $P$. oryzihabitans and B. megaterium. It is considered that the characterization of these microorganisms contributes to the evaluation of soil microbiota diversity as well as for definition of the use of these microorganisms in other studies of biotechnological interest.
\end{abstract}

Keywords: Grape. Biodiversity. Biotechnology. Agriculture. 


\section{INTRODUÇÃO}

A viticultura é uma atividade importante para a sustentabilidade da pequena propriedade no Brasil, como geração de emprego em grandes empreendimentos que produzem uvas de mesa e uvas para processamento. ${ }^{1}$ No Brasil, a atividade se iniciou no século XVI, em 1535, durante o período da colonização portuguesa. Porém, o estímulo maior para a produção ocorreu com a imigração italiana para São Paulo e para o Rio Grande do Sul, em fins do século XIX. ${ }^{2}$

A viticultura é uma atividade de extrema importância mundial. Segundo Melo, ${ }^{3}$ no Brasil, a videira é cultivada em uma grande diversidade de solos, sejam cultivos em solos altamente intemperizados, sejam cultivos em solos jovens com adequado suprimento de nutrientes. Por se tratar de um ambiente desafiador para estudos da ecologia microbiana, o solo abriga comunidades microbianas que aumentam em complexidade de acordo com a abundância delas. ${ }^{1}$ Os microorganismos são responsáveis pelos processos de mineralização, constituindo uma fonte de nutrientes potencialmente disponíveis para as plantas. ${ }^{2}$ Contudo, o uso de agentes químicos no combate a invasores da videira, assim como o cultivo intenso do solo ao longo dos anos, vêm modificando a microbiota original dos solos. ${ }^{4}$

No solo, a população microbiana é constituída principalmente por bactérias mas, apesar disso, a contribuição destas para a biomassa microbiana total é reduzida. ${ }^{5}$ No entanto, a biodiversidade presente pode fornecer isolados com características bioquímicas importantes para o desenvolvimento ou inibição de outros organismos, como produtoras de antibióticos, auxinas, solubilizadoras de fosfato, etc., ${ }^{4,6}$

A discussão sobre grupos que compõem as comunidades microbianas em solos ainda não está corretamente definida. ${ }^{1}$ Portanto, uma vez que estudos de identificação e avaliação de perfil bioquímico de isolados bacterianos de solo ainda são necessários, buscou-se avaliar parte dessa diversidade microbiana, contribuindo, assim, para a bioprospecção da biodiversidade bacteriana de solos.

\section{MATERIAL E MÉTODOS}

Todos os procedimentos de laboratório foram efetuados no Núcleo Biotecnológico da Universidade do Oeste de Santa Catarina de Videira.

\subsection{COLETA DAS AMOSTRAS}

Foram coletadas oito amostras de solo de diferentes cultivares de videiras localizadas nas $\mathrm{Ci}$ dades de Arroio Trinta ( $n=3)$, Salto Veloso $(n=2)$ e Videira $(n=3)$, em Santa Catarina. As coletas foram realizadas em maio de 2015. Todas as amostras de solo foram retiradas de áreas de parreirais entre quatro e 15 anos de produção. As amostras foram coletadas e transportadas para o laboratório para a realização das análises microbiológicas. 


\subsection{ISOLAMENTO DE BACTÉRIAS}

Para a pesquisa foram pesados $25 \mathrm{~g}$ de cada amostra e adicionados $225 \mathrm{~mL}$ de solução salina a $0,85 \%$ estéril. Em seguida, foram realizadas diluições decimais seriadas $\left(10^{-1}, 10^{-2}\right.$ e $\left.10^{-3}\right)$, em seguida, alíquotas de 0,1 mL foram transferidas em placas com Ágar PCA (Merck, Alemanha) (contagem total em placas) espalhamento com alça de Drigalski. Seguiu-se incubação a $30^{\circ} \mathrm{C}$. Aos meios foram previamente adicionados $20 \mu \mathrm{g}$ de Anfotericina B a cada $10 \mathrm{~mL}$ de Ágar para inibição de microbiota fúngica. Posteriormente, foram selecionadas as placas que continham entre 10 e 100 colônias, separando-se cerca de $10 \%$ do total de colônias obtidas em cada amostragem para análise morfofisiológica.

As análises microbiológicas iniciais consistiram em avaliação macroscópica de colônias crescidas em ágares, seleção de colônias isoladas e coloração de Gram. As análises bioquímicas foram realizadas considerando os dois grupos de bactérias: gram-positivas e gram-negativas.

\subsection{COLORAÇÃO DE GRAM E ANÁLISES BIOQUÍMICAS}

Para análise de coloração de Gram, duas a três colônias foram repicadas para as placas de PCA, incubadas a $30^{\circ} \mathrm{C}$ por 24 a 48 horas, seguindo-se a coloração de Gram.

a) teste catalase: para a prova da catalase foram preparados tubos com Caldo TSB (Triptico de Soja) e incubados a $30{ }^{\circ} \mathrm{C}$ por 24 horas. Em seguida, culturas de cada placa foram testadas

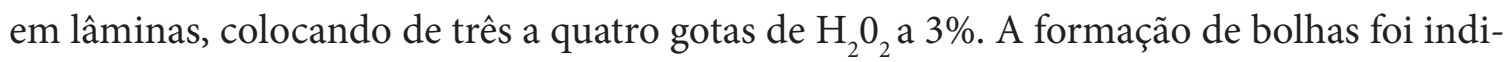
cativa da ação da catalase (catalase positiva);

b) teste indol: o teste do indol determina a capacidade que certas bactérias possuem de hidrolisar o triptofano e reduzi-lo a indol a partir da enzima triptofanase. A presença de indol é detectada pela adição do Reativo de Kovacs, em que ocorre a formação de um anel de coloração vermelha na superfície do meio, indicando uma reação positiva; ausência de mudança de cor indica que o triptofano não foi hidrolisado, portanto, a reação é negativa;

c) reação de hemólise: a partir de tubos contendo Caldo TSB (Himedia, Índia) foram feitas estrias nas placas contendo Ágar base (Himedia, Índia) suplementado com sangue de carneiro a $7 \%$. As placas foram incubadas a $30^{\circ} \mathrm{C}$ por 48 horas para avaliar as colônias típicas que apresentassem um halo transparente de hemólise;

d) teste de motilidade: foram inoculadas em Ágar SIM (Sulfeto Indol Motilidade) (Himedia, Índia) culturas de cada microorganismo a ser testado quanto à motilidade; na motilidade positiva, observa-se aspecto do meio turvo, e na motilidade negativa, o crescimento apenas no local de inoculação. Incubadas a $30{ }^{\circ} \mathrm{C}$ por 48 horas para análise dos resultados. 


\subsection{TESTES REALIZADOS COM ISOLADOS DE GRAM-NEGATIVAS}

a) identificação bioquímica: alíquotas de cada isolado identificado como gram-negativa foram suspensas em água destilada estéril com pH entre 6,8 e 7,2 até uma turbidez equivalente à escala de 0,5 de MacFarland. A partir disso, foi inoculado 1,0 mL da suspensão bacteriana a cada conjunto de provas de identificação bioquímica rápida (Laborclin, Brasil): ADH (Arginina), LDC (Lisina), ODC (Ornitina), $\mathrm{H}_{2} \mathrm{~S}$ (Tiossulfato de sódio), URE (Ureia), com incubação a $30^{\circ} \mathrm{C}$ por 24 horas. Após incubação e complementação das reações conforme indicação do fabricante, fez-se a leitura em software disponível on-line; ${ }^{7}$

b) antibiograma: para o teste antibiograma foram utilizadas as culturas crescidas em caldo TSB e inoculadas com o auxílio de swab estéril em placas de Ágar Mueller Hinton (Kasvi, Itália). Após 15 minutos foram postos discos de cada um dos seguintes antibióticos (DME, Brasil): Ceftriaxona (CRO), Tetraciclina (TET), Cefepima (CPM), Pipemídico (PIT), Cefoxitina (CFO), Amoxicilina + Ac. Clavulânico (AMC), Sulfonamidas (SUL), Ciprofloxacino (CIP), Cefalotina (CFL), Gentamicina (GEN), Cloranfenicol (CLO), Ceftazidima (CAZ), Ampicilina (AMP), Aztreonam (ATM) e Amicacina (AMI). As placas foram incubadas a $30{ }^{\circ} \mathrm{C}$ por 24 horas.

\subsection{TESTES REALIZADOS APENAS COM ISOLADOS DE BACTÉRIAS GRAM-POSITIVAS}

a) solubilização de fosfatos inorgânicos (Ca3(PO4)2): utilizou-se o método conforme Nautiyal $^{8}$ para avaliar a capacidade dos isolados em solubilizar fosfato inorgânico. Os isolados foram repicados em placas de Ágar com incubação por dias a $30^{\circ} \mathrm{C}$. Após o período de incubação, foi observada a presença ou ausência de halo de solubilização em torno das colônias;

b) produção de sideróforos: os ensaios foram realizados em meio King B, ${ }^{9}$ adicionado ao meio a solução indicadora de cromo azurol (CAS). Segundo a metodologia descrita e adaptada por Biasiolo, ${ }^{10}$ os isolados foram cultivados em tubos de ensaio contendo $5 \mathrm{~mL}$ de meio King B, mantidos por 24 horas a $30^{\circ} \mathrm{C}$ sob agitação constante. Uma alíquota de $100 \mu \mathrm{L}$ foi transferida para placas contendo o mesmo meio. As placas foram incubadas a $30{ }^{\circ} \mathrm{C}$ por 72 horas. A presença de halo amarelo/laranja ao redor das colônias foi indicativo de resultado positivo para produção de sideróforos. 


\subsection{CLASSIFICAÇÃO TAXONÔMICA}

A classificação das bactérias gram-positivas foi realizada conforme chave de identificação bacteriana descrita por Brown, ${ }^{11}$ considerando os testes:

a) formação de endósporos: foram utilizadas culturas crescidas por 24 horas Ágar; alíquotas $(10 \mu \mathrm{L})$ foram adicionadas em lâminas de vidro e cobertas com papel toalha, adicionando-se o reagente verde de malaquita. A lâmina foi posta por cinco minutos sobre vapor fluente, seguindo-se lavagem em água destilada; coloração por 30 segundos com solução de fucsina e lavagem em água destilada. Por microscopia observou-se a presença ou não de esporos. Para os isolados formadores de esporos seguiu-se o teste do manitol e para os isolados não formadores de esporos fez-se o teste do citrato;

b) teste utilização do manitol: os isolados foram inoculados em Ágar Sal Manitol (Oxoid, Inglatera) e incubados a $30^{\circ} \mathrm{C}$ por 36 horas para análise dos resultados. A presença de mudança de cor do meio rosado para amarelo representou resultado positivo para produção de ácidos;

c) teste do Voges-Proskauer-VP e Vermelho de Metila-MR: foram inoculadas os isolados que obtiveram resultado positivo ao teste do manitol, em caldo VP e caldo MR (HiMedia, Brasil). Incubadas a $30{ }^{\circ} \mathrm{C}$ por 24 horas. Para o teste do VP utilizou-se o reagente $\alpha$-naftol e hidróxido de potássio a 40\% (Sigma- Aldrich, Brasil). Para o teste MR utilizou-se solução de Vermelho de Metila 0,1\% em etanol (95\%);

d) teste do Citrato: os isolados que obtiveram resultado negativo ao teste do manitol foram repicados em tubos com Ágar Citrato Simmons (Merck, Alemanha) inclinado e incubadas a $30^{\circ} \mathrm{C}$ por 24 horas. Observou-se a mudança de coloração do meio verde para azul ou não.

\section{RESULTADOS}

Dos 21 isolados bacterianos de amostras de solos de diferentes cultivares de videira (Vitis $s p$.), 60,86\% eram bactérias gram-negativas $(\mathrm{n}=13)$, e $39,13 \%$ gram-positivas $(\mathrm{n}=8)$, predominando morfologia bacilar.

As bactérias gram-negativas foram avaliadas preliminarmente quanto à produção de indol, atividade de catalase, reação de hemólise e motilidade (Tabela 1). 
Tabela 1 - Testes bioquímicos preliminares realizados em isolados bacterianos de gram-negativas de amostras de solo de cultivo de videira ${ }^{\dagger}$

\begin{tabular}{lcccc}
\hline \multicolumn{1}{c}{ Isolados } & Atividade de catalase & Motilidade & $\begin{array}{c}\text { Reação de Kovac's } \\
\text { (Triptofano) }\end{array}$ & $\begin{array}{c}\text { Teste de hemólise } \\
\text { Códigos }\end{array}$ \\
\hline BSV 03 & + & + & - & - \\
BSV 06 & + & - & - & + \\
BSV 07 & + & + & - & + \\
BSA 09 & + & + & - & + \\
BSA 10 & + & + & - & + \\
BSA 11 & + & + & - & + \\
BSA 12 & + & + & - & + \\
BSS 15 & + & + & - & + \\
BSS 18 & + & + & - & + \\
BSS 19 & + & + & - & + \\
BSS 22 & + & + & - & + \\
BSS 23 & + & + & - & + \\
BSS 24 & + & & - & + \\
\hline
\end{tabular}

Em seguida aos testes bioquímicos iniciais, foram realizadas também outras análises bioquímicas com base na assimilação de carboidratos e aminoácidos (Laborclin, São Paulo) de cada isolado. Os resultados revelaram que $92,3 \%(\mathrm{n}=12)$ dos isolados foram identificados como da espécie Shigella dysenteriae soro grupo A e 7,7\% (n=1), da espécie Pseudomonas oryzihabitans.

O perfil de sensibilidade a antimicrobianos foi avaliado para os isolados de gram- negativas considerando que as duas espécies definidas são patogênicas recorrentes em infecções humanas de origem ambiental. ${ }^{4} \mathrm{Na}$ Figura 1 apresenta-se o resultado do percentual de sensibilidade/resistência a cada um dos antimicrobianos testados. Verificou-se que $100 \%$ dos isolados foram sensíveis a somente três dos antibióticos (Gentamicina, Pipemídico e Cloranfenicol) testados e tiveram resistência de $100 \%$ a outros dois (Ceftazidina e Aztreonam). Destacou-se o isolado BSS 19 como o que mais apresentou inibição aos antibióticos testados (86,66\%), enquanto os isolados BSA 11 e BSS 22 tiveram o menor índice (26\%).

A avaliação do perfil de sensibilidade/resistência não interfere necessariamente no desenvolvimento de plantas, mas pode ser um fator a ser considerado se combinações de isolados forem utilizadas na composição de substratos em solo.

\footnotetext{
${ }^{\dagger}$ Legenda: $(+)$ = Positivo; $(-)$ = Negativo. Origem: BSV = Videira, BSA = Arroio Trinta e BSS = Salto Veloso.
} 


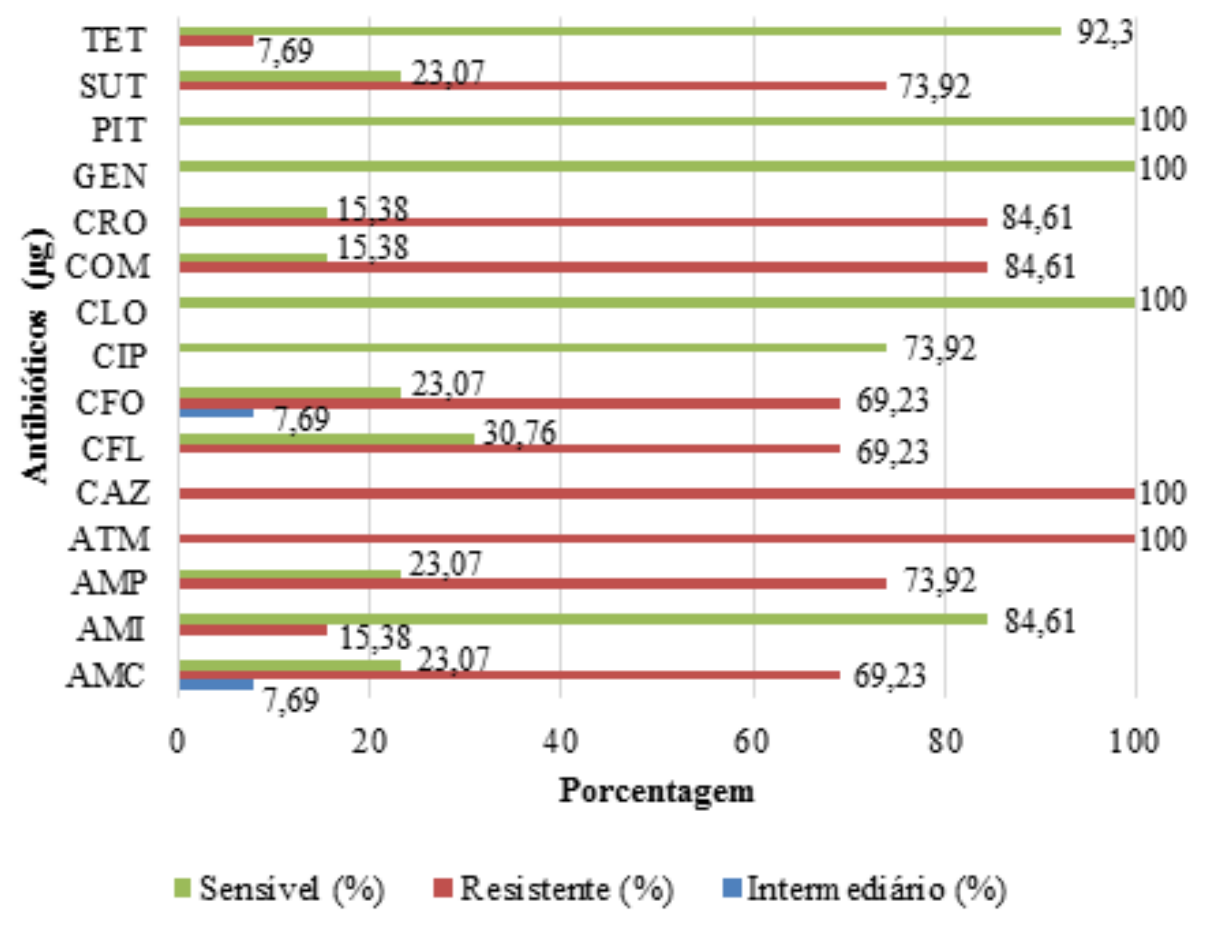

Figura 1 - Percentual de bactérias gram-negativas em relação ao perfil de sensibilidade a antimicrobiano

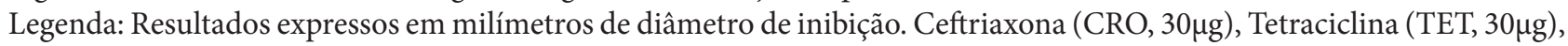

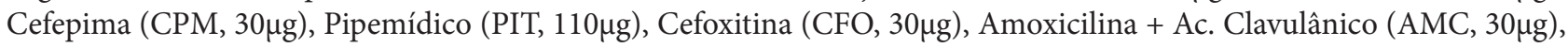

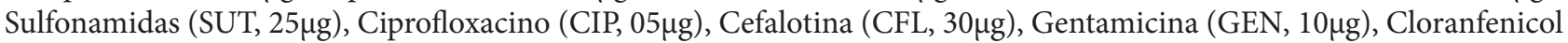

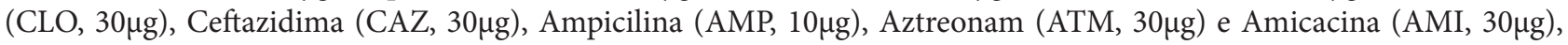
(DME, Brasil).

Em relação aos isolados de bactérias gram-positivas, elas também foram avaliadas preliminarmente quanto à produção de indol, atividade de catalase, reação de hemólise e motilidade (Tabela 2).

Tabela 2 - Teste de identificação bioquímica de bactérias gram-positivas de amostras de solo de parreirais em municípios catarinenses ${ }^{\ddagger}$

\begin{tabular}{|c|c|c|c|c|}
\hline $\begin{array}{l}\text { Isolados } \\
\text { Códigos }\end{array}$ & Atividade de catalase & $\begin{array}{c}\text { Teste de } \\
\text { Motilidade }\end{array}$ & $\begin{array}{c}\text { Reação de Kovac's } \\
\text { (Triptofano) }\end{array}$ & Teste de Hemólise \\
\hline BSV 02 & + & + & - & + \\
\hline BSV 04 & + & + & - & + \\
\hline BSV 05 & + & + & - & + \\
\hline BSA 08 & + & + & - & + \\
\hline BSA 13 & + & - & - & - \\
\hline BSA 14 & + & + & - & + \\
\hline BSS 16 & + & + & - & + \\
\hline BSS 17 & + & + & - & + \\
\hline
\end{tabular}

Quanto à capacidade de solubilização de fosfatos inorgânicos $\left(\mathrm{Ca}_{3}\left(\mathrm{PO}_{4}\right)_{2}\right)$, somente a amostra BSV05 foi positiva. E para a produção de sideróforos, dois isolados mostraram-se produtores: BSA08 e BSA13.

\footnotetext{
${ }^{\ddagger}$ Legenda: $(+)$ = Positivo; $(-)=$ Negativo. Origem: BSV = Videira, BSA = Arroio Trinta e BSS = Salto Veloso.
} 
Todos os isolados foram identificados em nível de espécie com base nos dados morfofisiológicos. As gram-positivas foram identificadas como: Bacillus cereus $(\mathrm{n}=1)$, Bacillus megaterium $(\mathrm{n}=4)$ e Corynebacterium xerosis $(n=1)$ Corynebacterium pseudodiphtheriticum $(n=2)$. Para as gram-negativas, duas espécies foram determinadas, sendo $92,3 \%(n=12)$ como Shigella dysenteriae soro grupo A e $7,7 \%(n=1)$ como pertencente à espécie Pseudomonas oryzihabitans.

\section{DISCUSSÃO}

As bactérias gram-positivas e gram-negativas compõem o grupo das Eubactérias (Bacteria) que têm parede celular composta por uma camada de peptidioglicano, o qual se apresenta estreito nas gram-negativas (10-15nm) e mais espesso (20-30nm) nas gram- positivas. ${ }^{12}$ Nestas últimas, a parede contém polissacarídeos e/ou ácidos teicoicos. Nas gram- negativas existe ainda uma membrana externa composta por proteínas e lipopolissacaridio. ${ }^{13} \mathrm{Na}$ Figura 2 é apresentado um esquema das estruturas das paredes celulares de gram-positivas e de gram-negativas.

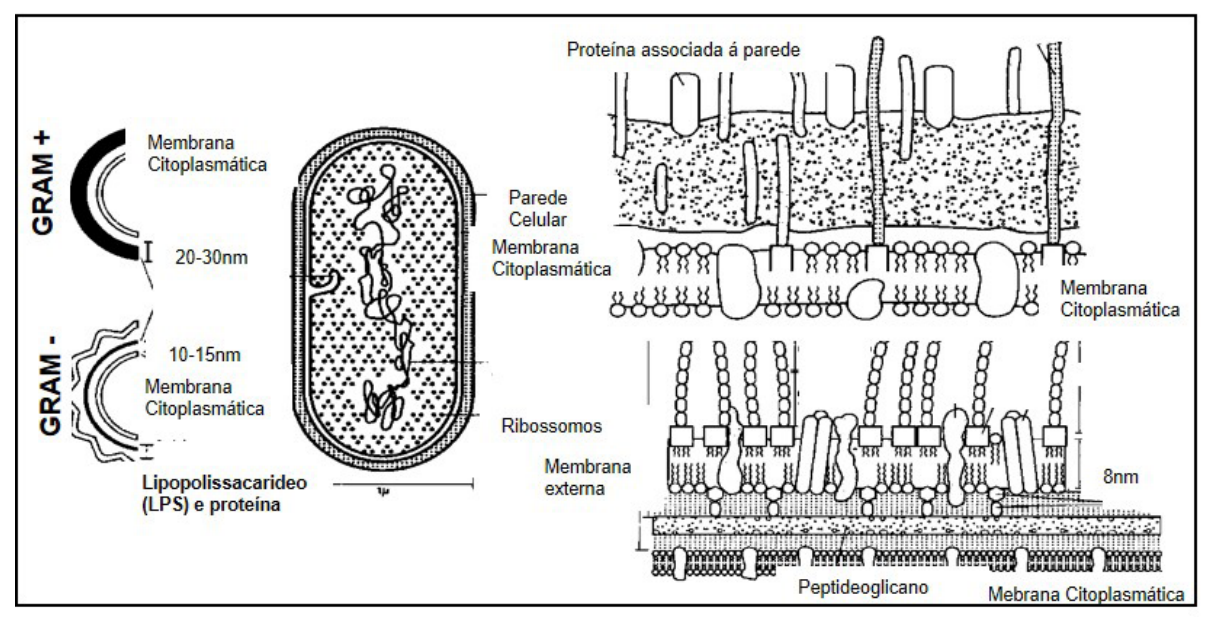

Figura 2 - Esquema das estruturas das paredes celulares de gram-positivas e de gram-negativas Fonte: adaptado de Morreira e Siqueira. ${ }^{13}$

Entre as bactérias gram-positivas, dois dos isolados apresentaram características fisiológicas de importância para estudos visando à utilização como coadjuvantes na qualidade do solo e desenvolvimento vegetal. Destacou-se a espécie Bacillus megaterium, pela capacidade de solubilizar fosfatos naturais existentes no solo. Linhagens dessa espécie têm sido utilizadas também por sua capacidade de biodegradação, sendo produtoras de Poli-3-hidroxibutirato (P3HB). ${ }^{14}$

A espécie Pseudomonas oryzihabitans é uma gram-negativa que tem sido associada a enfermidades de saúde pública relacionadas a águas contaminadas. ${ }^{15}$ No presente estudo, nessas condições é provável que o manejo do solo em algumas áreas do cultivo esteja falhando nos aspectos de higiene básica, como, por exemplo, com água contaminada com fezes ou mesmo por contaminação direta com fezes humanas ou, ainda, outro tipo de matéria orgânica, o que pode se constituir em risco à 
saúde do trabalhador rural. Por outro lado, há registro de que linhagens endofíticas dessa espécie são promotoras do crescimento vegetal por diferentes mecanismos, como produção de auxinas e solubilização de fosfatos, bem como utilização do glifosato como única fonte de carbono. ${ }^{15} \mathrm{O}$ fornecimento de fósforo para as plantas por microorganismos solubilizadores de fosfato contribui para o melhor crescimento e rendimento de culturas vegetais. ${ }^{16}$

\section{CONSIDERAÇÕES FINAIS}

Os microrganismos desempenham papel importante na qualidade do solo em face à diversidade metabólica destes que, por sua vez, contribui para o desenvolvimento vegetal. ${ }^{1}$ Estima-se que a diversidade da microbiota de solos utilizados em cultivo de plantas seja grande. Certamente, o manejo constante do solo e o uso de agroquímicos podem alterar essa biota e sua diversidade. Contudo, muito ainda há a ser explorado.

Neste estudo, um pouco dessa microbiota bacteriana pôde ser avaliada, prospectando-se linhagens com potencial para estudos que envolvam o desenvolvimento de plantas de interesse econômico.

\section{REFERÊNCIAS}

1. Andreote FD, Cotta SR, Dias ACF. Microbioma de solos brasileiros: uma visão geral. Revista Microbiologia in Foco [Internet]. 2015 [acesso em 10 out 2016 ; 6(26): 22-39. Disponível em: http:// sbmicrobiologia.org.br/wp-content/uploads/2015/09/REVISTA-SBM-EDI----O-26-p-site.pdf

2. Gava AJ, Silva CAB, Gava JRF. Tecnologia de alimentos: princípios e aplicações. São Paulo: Nobel; 2009.

3. Melo GW. Adubação e manejo do solo para a cultura da videira. Embrapa Uva e Vinho. [Internet]. 2003. [acesso em 10 out 2016] . Disponível em: http://www.cnpuv.embrapa.br/publica/ sprod/viticultura/adubvid.html

4. JAY JM. Microbiologia de alimentos. 6 $6^{\text {a }}$ ed. Porto Alegre: Artmed; 2005.

5. Martins KF. Determinação da população de fungos e bactérias do solo contaminado com petróleo e armazenado sob refrigeração e congelamento [dissertação]. Curitiba: Universidade Federal do Paraná, Setor de Ciências Agrárias; 2002.

6. Pelczar M Jr, Chan ECS, Krieg, NR. Microbiologia: conceitos e aplicações. $2^{\text {a }}$ ed. $8^{\text {a }}$ reimp. São Paulo: Pearson Education do Brasil; 2013. v.2. 
7. Laborclin Produtos para Laboratórios Ltda. Kit Para Enterobactérias. Pinhais. [acesso em 10 out 2016 . Disponível em: http://www.laborclin.com.br/produto.asp?id=510918

8. Nautiyal CS. An efficient microbiological growth medium for screening phosphate solubilizing microorganisms. FEMS Microbiol Lett. 1999 Jan; 170(1): 265-70.

9. King EO, Ward MK, Raney DE. Two simple media for the demonstration of pyocyanin and fluorescein. J Lab Clin Med. 1954; 44(2): 301-7.

10. Biasiolo GAD. Isolamento, caracterização e seleção de bactérias promotoras de crescimento vegetal de videira (Vitis sp) [dissertação]. Videira: Universidade do Oeste de Santa Catarina; 2015.

11. Brown AE. Benson's Microbiological Applications. Laboratory manual in general microbiology. 10a ed. New York: McGraw Hill; 2007.

12. Holt JG, Krieg NR, Sneath PHA; Staley JT, Williams ST. Bergey's Manual of Determinative Bacteriology. Baltimore: Williams \& Wilkins; 1994.

13. Morreira FMS, Siqueira JO. Microbiologia dos solos. $2^{\mathrm{a}}$ ed. Lavras: UFLA; 2006.

14. Luvizetto DJ. Cultivo da bactéria Bacillus megaterium para a produção do biopolímero poli(2-hidroxibutirato) e modelagem matemática do bioprocesso [dissertação]. Porto Alegre: Universidade Federal do Rio Grande do Sul; 2007.

15. Sobral JK. A comunidade bacteriana endofítica e epifítica de soja (Glycine max) e estudo da interação endófitos-planta [tese]. Piracicaba: Universidade de São Paulo; 2003.

16. Silva Filho GN, Vidor C. Solubilização de fostatos por microrganismos na presença de fontes de carbono. R Bras Ci Solo 2000; 24: 311-9.

Data da submissão: 01 de dezembro de 2016 Aceito em: 14 de dezembro de 2016 
